\title{
BMJ Open Is postoperative decrease of serum albumin an early predictor of complications after major abdominal surgery? A prospective cohort study in a European centre
}

Ismail Labgaa, Gaëtan-Romain Joliat, Amaniel Kefleyesus, Styliani Mantziari, Markus Schäfer, Nicolas Demartines, Martin Hübner

To cite: Labgaa I, Joliat G-R, Kefleyesus A, et al. Is postoperative decrease of serum albumin an early predictor of complications after major abdominal surgery? A prospective cohort study in a European centre. BMJ Open 2017;7: e013966. doi:10.1136/ bmjopen-2016-013966

- Prepublication history and additional material is available. To view please visit the journal (http://dx.doi.org/ 10.1136/bmjopen-2016013966)

$\overline{\mathrm{IL} \text { and G-RJ contributed }}$ equally.

The present study was presented at the 103rd Congress of Swiss Surgery (June 2016, Lugano, Switzerland) and at the Clinical Congress of the American College of Surgeons (October 2016, Washington, DC, USA)

Received 25 August 2016 Revised 10 February 2017 Accepted 21 February 2017

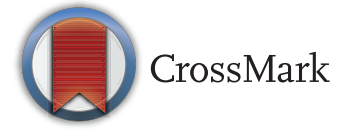

For numbered affiliations see end of article.

Correspondence to Dr Nicolas Demartines; demartines@chuv.ch

\section{ABSTRACT}

Objective: To test postoperative serum albumin drop $(\triangle \mathrm{Alb})$ as a marker of surgical stress response and early predictor of clinical outcomes.

Design: Prospective cohort study (NCT02356484). Albumin was prospectively measured in 138 patients undergoing major abdominal surgery. Blood samples were collected before surgery and on postoperative days 0,12 and $3 . \Delta$ Alb was compared to the modified estimation of physiologic ability and surgical stress (mE-PASS) score and correlated to the performances of $C$ reactive protein (CRP), procalcitonin (PCT) and lactate (LCT). Postoperative outcomes were postoperative complications according to Clavien classification and Comprehensive Complication Index (CCI), and length of hospital stay (LoS).

Setting: Department of abdominal surgery in a European tertiary centre.

Participants: Adult patients undergoing elective major abdominal surgery, with anticipated duration $\geq 2$ hours. Patients on immunosuppressive or antibiotic treatments before surgery were excluded.

Results: The level of serum albumin rapidly dropped after surgery. $\triangle$ Alb correlated to the $\mathrm{mE}$ PASS score $(r=0.275, p=0.01)$ and to CRP increase $(r=0.536, p<0.001) . \Delta$ Alb also correlated to overall complications $(r=0.485, p<0.001), \mathrm{CCl}(r=0.383$, $p<0.001)$ and LoS $(r=0.468, p<0.001)$. A $\Delta$ Alb $\geq 10 \mathrm{~g} / \mathrm{L}$ yielded a sensitivity of $77.1 \%$ and a specificity of $67.2 \%$ (AUC: $78.3 \%$ ) to predict complications. Patients with $\triangle \mathrm{Alb} \geq 10 \mathrm{~g} / \mathrm{L}$ on POD 1 showed a threefold increased risk of overall postoperative complications.

Conclusions: Early postoperative decrease of serum albumin correlated with the extent of surgery, its metabolic response and with adverse outcomes such as complications and length of stay. A decreased concentration of serum albumin $\geq 10 \mathrm{~g} / \mathrm{L}$ on POD 1 was associated with a threefold increased risk of overall postoperative complications and may thus be used to identify patients at risk.

\section{Strengths and limitations of this study}

- The present study has a prospective design and offers a head-to-head comparison with biomarkers currently used in clinical practice ( $\mathrm{C}$ reactive protein and procalcitonin).

- Albumin drop was thoroughly assessed by analyzing its correlation with a comprehensive panel of surrogate markers for surgical trauma and validated scores for outcomes.

- The predictive value of combined biomarkers was not assessed in the present study.

- This study involved a single centre and included a training cohort, without validation cohort.

\section{INTRODUCTION}

Abdominal surgery is among the most frequently performed elective surgery. ${ }^{1}$ Although surgical and perioperative improvements have reduced postoperative mortality over the last few decades, postoperative morbidity has remained high. ${ }^{2}$ In addition to the morbidity which patients are exposed to, postoperative complications pose a significant financial burden, while important efforts are currently pursued to reduce healthcare expenditures. $^{2}$

The magnitude of metabolic stress response mirrors the extent of surgery ${ }^{3} 4$ and presumably contributes to the risk of developing postoperative complications. ${ }^{56}$ Early identification of patients at risk may improve outcomes, since measures to attenuate the surgical stress response and to reduce morbidity exist. ${ }^{7}$

Although $\mathrm{C}$ reactive protein (CRP) and procalcitonin (PCT) have been proposed as predictors for adverse outcomes in colorectal surgery, they both display the critical limitation of slow kinetics. ${ }^{9}$ Conversely, serum 
albumin (Alb) is a maintenance protein that is rapidly downregulated by inflammatory signals. ${ }^{40}$ Preliminary data suggested that Alb level rapidly dropped after surgery and correlated to outcomes in esophageal, ${ }^{11}$ oral cancer, ${ }^{12}$ abdominal ${ }^{4}$ pancreatic, ${ }^{13}$ liver resection ${ }^{14}$ / transplant ${ }^{15}$ and cardiac ${ }^{16}$ surgeries. However, prospective validation is missing, and Alb is not used to assess surgical stress or to predict outcomes.

This study aimed to test the hypotheses that early postoperative albumin drop (1) reflects the magnitude of surgical trauma, (2) correlates to established markers of metabolic stress and (3) predicts postoperative complications.

\section{METHODS}

Study design and patient groups

This prospective study was conducted at the Department for Visceral Surgery at the University Hospital of Lausanne Switzerland (CHUV) between February and December 2015 (NCT02356484). The study was approved by the Institutional Review Board (No. 367/ 15), and all patients provided written consent prior to surgery. Inclusion criteria were age $>18$ years, and elective major abdominal surgery-defined as an operative procedure with anticipated duration $\geq 2$ hours. ${ }^{17}$ Perioperative care closely adhered to recently published enhanced recovery guidelines (http://erassociety.org. loopiadns.com/guidelines/list-of-guidelines). Standardised fluid administration was followed by advanced haemodynamic monitoring to avoid intraoperative fluid overload. According to the clinical care pathway, intravenous fluid was typically discontinued the morning after surgery.

Demographics, comorbidities, surgical details and clinical outcomes were prospectively collected and anonymised in a computerised protected database. A twosample t-test was used to calculate sample size, with size effect of 0.8 , power of 0.99 and significance level of 0.05 . This determined a required number of 50 patients per group (ie, with complication vs without complication). Anticipating a complication rate of $40 \%$, the final sample size for this study was $\mathrm{n}=125$ patients. In order to adjust for $10 \%$ dropout or missing data, final sample size resulted in $\mathrm{n}=138$.

\section{Extent of surgery}

The amplitude of surgical stress was measured by the modified estimation of physiologic ability and surgical stress (mE-PASS). Briefly, mE-PASS score encompasses seven items (six preoperative variables and the surgical procedure). It predicts the in-hospital mortality and the 30-day mortality rates, respectively. ${ }^{18}$ Type of surgery, operative time and surgical approach (open vs laparoscopic) were recorded. Conversions from laparoscopy to laparotomy were counted as laparoscopic cases. Anaesthesiologists and surgeons jointly estimated blood loss by measuring the volume of aspirated fluid and soaked gauzes.

\section{Biological markers}

Serum levels of albumin, CRP, PCT and lactate (LCT) were perioperatively measured in a fasting state, following standardised institutional guidelines. Blood samples were drawn the day before surgery, the day of surgery (4-6 hours after the end of the operation) and on the first, second and third postoperative day. As baseline values tend to show large variations especially for albumin, ${ }^{410}$ we considered that a dynamic value (difference between two time-points) might be more informative than a snapshot value. Several values based on preoperative and postoperative concentrations were thus calculated for each marker (ie, $\Delta$ Max: maximal difference between the preoperative and postoperative values; $\triangle$ POD 0: difference of concentration on POD -1 and POD $0 ; \Delta$ POD 1: difference of concentration on POD -1 and POD 1).

\section{Outcome measures}

Complications were graded with the Clavien classification within 30 postoperative days, counting grade I/II events as minor complications and grades III and $\mathrm{V}$ as major complications. ${ }^{19}$ Every complication was documented. Global morbidity for each patient was quantified by the comprehensive complication index (CCI) on a scale from 0 to $100,{ }^{20}$ representing respectively no complication and postoperative death. Length of stay (LoS) was considered to be the duration from the day of surgery until discharge.

\section{Statistical analysis}

Continuous variables were presented as mean with SD or median value with IQR depending on the normality of the distribution and compared using Student's $t$-test and Mann-Whitney $U$ test, whereas categorical variables were given as frequencies with percentages and compared with $\chi^{2}$ test. For statistical analyses, the following parameters were dichotomised: age ( $\geq 70$ years), body mass index $\left(\geq 25 \mathrm{~kg} / \mathrm{m}^{2}\right)$, operative time $(\geq 180 \mathrm{~min})$ and blood loss $(\geq 200 \mathrm{~mL})$. Spearman's and Pearson's tests were used to measure correlations of categorical (p) and continuous (r) variables, respectively. Receiver operating characteristic (ROC) curves were applied to obtain the area under the curve (AUC) and to determine ideal cut-offs. Logistic regression was applied to identify independent predictors; variables with significance $<0.1$ in univariable analyses were further included in multivariable analyses. A $p$ value $<0.05$ was considered to be statistically significant in all tests. Data analyses were generated using SPSS V.20 statistical software (Chicago, Illinois, USA).

\section{RESULTS}

Patients characteristics, details of surgery and outcomes During the study period, 155 consecutive patients undergoing major abdominal surgery were potentially eligible for inclusion, but 17 of them refused to participate. As a 
result, 138 patients were included in the study and had a complete follow-up. Demographics and surgical details are displayed in table 1 . The median mE-PASS score was 0.66 (IQR 0.45-0.96).

Overall, 60/138 patients (43\%) experienced at least one complication, and one patient died after total gastrectomy and splenopancreatectomy due to cardiorespiratory arrest. Minor and major complications were observed in 35 and 25 patients, respectively. Patients showed a mean CCI of 13.2 (SD 18.5), and were discharged after a median LoS of 8 days (IQR 5-15 days).

\section{Perioperative profile of biomarkers}

The perioperative profile of albumin showed a rapid drop induced by surgery, followed by a plateau phase between POD 0 and POD 3 (see online supplementary figure S1). LCT levels peaked in the first 4-6 hours after surgery and were back to baseline on POD1. Conversely, CRP and PCT showed slow kinetics reaching maximal values on POD 4 and 3, respectively. The mean maximal decrease of albumin was $11.3 \mathrm{~g} / \mathrm{L}( \pm 5.6)$, which was similar to albumin drop on POD 1: $10.1 \mathrm{~g} / \mathrm{L}$ (SD: 5.8). Further analyses were hence focused on $\triangle$ Alb on POD1.

\section{Correlation of $\Delta$ Alb to surgical stress, biomarkers and outcomes}

$\triangle$ Alb on POD1 correlated to surgical stress (mE-PASS) $(\mathrm{r}=0.275, \mathrm{p}=0.01)$ and to surrogates such as duration of surgery $(\mathrm{r}=0.562, \mathrm{p}<0.001)$, blood loss $(\mathrm{r}=0.391, \mathrm{p}<0.001)$ and surgical approach $(\mathrm{p}=0.55, \mathrm{p}<0.001)$ (figure 1$)$.

$\triangle$ Alb on POD1 also correlated to maximal increases of CRP $(\mathrm{r}=0.54, \mathrm{p}<0.001)$, PCT $(\mathrm{r}=0.43, \mathrm{p}<0.001)$ and LCT $(\mathrm{r}=0.25, \mathrm{p}=0.02)$. Furthermore, a positive and significant correlation was highlighted between $\triangle \mathrm{Alb}$ on POD1 and

Table 1 Baseline characteristics of patients with and without postoperative complications

\begin{tabular}{|c|c|c|c|}
\hline & $\begin{array}{l}\text { Patients with complications }(n=60) \\
\text { n (\%) }\end{array}$ & $\begin{array}{l}\text { Patients without complications }(n=78) \\
\text { n (\%) }\end{array}$ & p Value \\
\hline \multicolumn{4}{|l|}{ Demographics } \\
\hline Median age (years)* & $64(50-73)$ & $59(51-69)$ & 0.306 \\
\hline Age $\geq 70$ years & $20(51)$ & $19(49)$ & 0.246 \\
\hline Gender (male) & $38(63)$ & $34(44)$ & 0.021 \\
\hline Median BMI $\left(\mathrm{kg} / \mathrm{m}^{2}\right)^{*}$ & $24(22-28)$ & $26(22-31)$ & 0.038 \\
\hline $\mathrm{BMI} \geq 25 \mathrm{~kg} / \mathrm{m}^{2}$ & $27(47)$ & $46(60)$ & 0.128 \\
\hline \multicolumn{4}{|l|}{ Comorbidities } \\
\hline ASA (I-II) & $36(60)$ & $52(67)$ & 0.419 \\
\hline ECOG $(0-1)$ & $45(75)$ & $66(85)$ & 0.158 \\
\hline Cirrhosis & 2 (3) & $1(1)$ & 0.413 \\
\hline Heart disease & $10(17)$ & $12(16)$ & 0.864 \\
\hline Lung disease & $8(13)$ & $7(9)$ & 0.415 \\
\hline Diabetes & $8(13)$ & $13(17)$ & 0.589 \\
\hline History of surgery & $33(55)$ & $42(55)$ & 0.958 \\
\hline Cancer & $45(75)$ & 54 (69) & 0.456 \\
\hline \multicolumn{4}{|l|}{ Surgery } \\
\hline \multicolumn{4}{|l|}{ Type } \\
\hline Colorectal & $14(23)$ & $17(22)$ & 0.840 \\
\hline HPB & $31(52)$ & $19(24)$ & 0.001 \\
\hline Upper-GI & $11(18)$ & $17(22)$ & 0.674 \\
\hline Other & $4(7)$ & $25(32)$ & $<0.001$ \\
\hline Approach & & & $<0.001$ \\
\hline Open & $50(83)$ & $29(37)$ & \\
\hline Laparoscopy & $10(17)$ & $49(63)$ & \\
\hline \multicolumn{4}{|l|}{ Duration } \\
\hline Median $(\min )^{*}$ & $271(224-340)$ & 154 (112-239) & $<0.001$ \\
\hline$\geq 180 \mathrm{~min}$ & $46(77)$ & $33(42)$ & $<0.001$ \\
\hline \multicolumn{4}{|l|}{ Blood loss } \\
\hline Median $(\mathrm{mL})^{*}$ & $300(100-575)$ & $90(0-263)$ & 0.002 \\
\hline$\geq 200 \mathrm{~mL}$ & $40(67)$ & $24(31)$ & $<0.001$ \\
\hline Intravenous fluid (mL) & $2500(2000-4000)$ & 1500 (1000-2500) & 0.018 \\
\hline Median mE-PASS & $0.77(0.57-1.03)$ & $0.49(0.4-0.81)$ & 0.12 \\
\hline \multicolumn{4}{|c|}{$\begin{array}{l}\text { Other surgeries included pressurised intra-abdominal aerosol chemotherapy (17), endocrine operations (4), complex abdominal wall } \\
\text { operations (2), resections of retroperitoneal sarcomas (3), nephrectomy (1) and interrupted limb perfusions for melanoma (2). } \\
\text { *Median values (IQR). } \\
\text { ASA, American Association of Anesthesiologists physical status classification system; BMI, body mass index; CCI, Comprehensive } \\
\text { Complication Index; ECOG, Eastern Cooperative Oncology Group performance status; cancer: operative indication; HPB, } \\
\text { hepato-pancreatico-biliary surgery; LoS, length of stay; mE-PASS, modified estimation of physiologic ability and surgical stress; Upper-GI, } \\
\text { upper-gastrointestinal surgery. }\end{array}$} \\
\hline
\end{tabular}



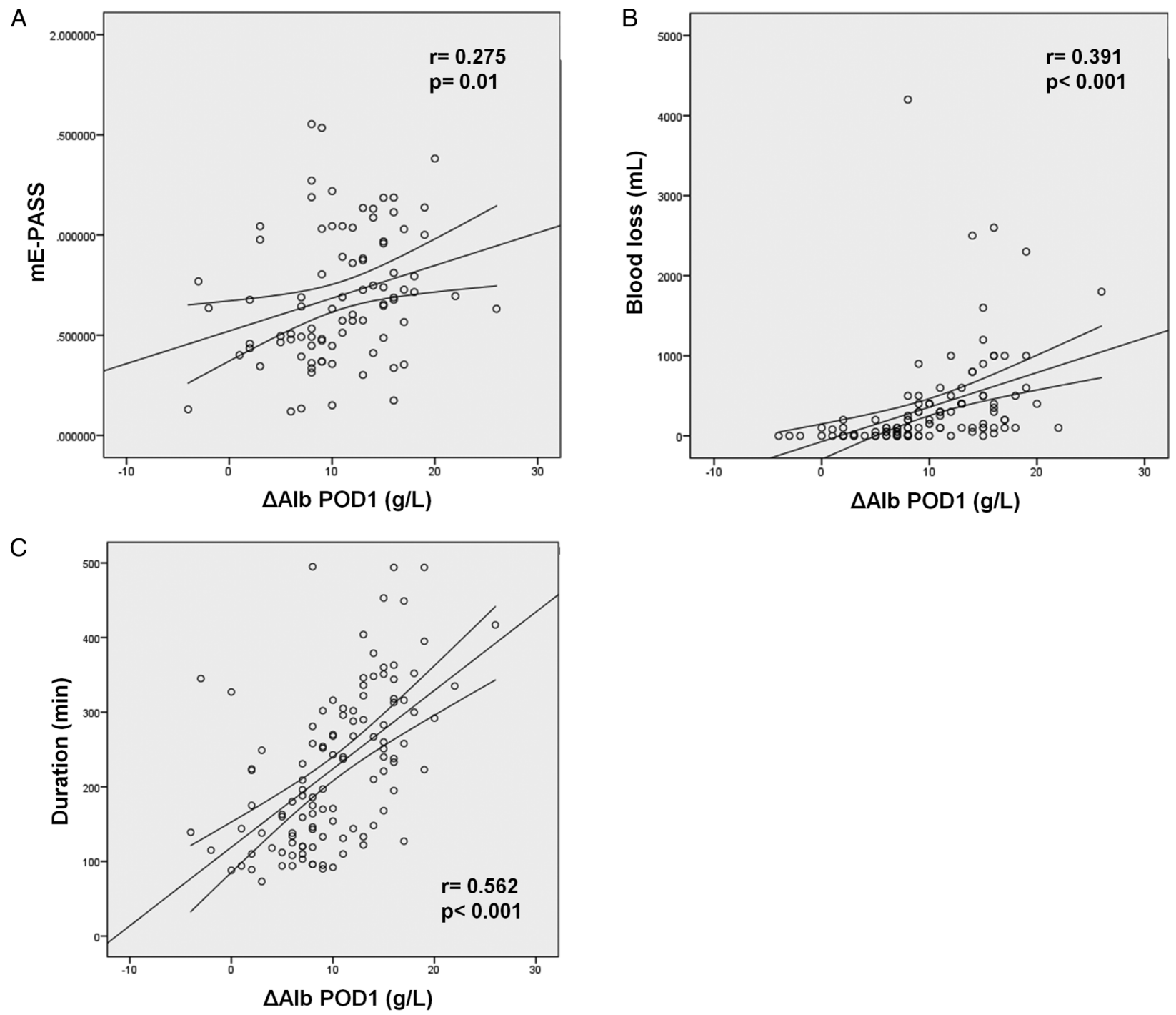

Figure $1 \Delta$ Alb on POD1 correlates with the extent of surgery. $\triangle$ Alb on POD1 showed a significant correlation with (A) mE-PASS $(r=0.275, p=0.01)$, (B) blood loss $(r=0.391, p<0.001)$ and $(C)$ duration of surgery $(r=0.562, p<0.001)$.

$\Delta \mathrm{CRP}$ on POD4 $(\mathrm{p}=0.234, \mathrm{p}=0.044) . \Delta$ Alb on POD1 was significantly associated with adverse outcomes, showing significant correlations with CCI $(\mathrm{p}=0.383, \mathrm{p}<0.001)$ and $\operatorname{LoS}(\mathrm{p}=0.468, \mathrm{p}<0.001)$ (figure 2$)$.

The correlations of CRP, PCT and LCT with surgical stress and outcomes were also tested and are detailed in online supplementary table S1.

\section{Predictive value of albumin decrease}

A ROC curve was used to determine the optimal cut-off of $\triangle \mathrm{Alb}$ on POD 1 , settled at $10 \mathrm{~g} / \mathrm{L}$. The area under the curve (AUC) measured $78.3 \%$ (95\% CI $70 \%$ to $87 \%$ ), giving a sensitivity of $77.1 \%$, a specificity of $67.2 \%$, a positive predictive value of $64.8 \%$ and a negative predictive value of $79.6 \%$, for overall complications (figure 3). The respective ROC curves for POD1 values of $\triangle \mathrm{CRP}$, $\triangle \mathrm{PCT}$ and $\triangle \mathrm{LCT}$ are provided in online supplementary figure S2.

It was subsequently investigated whether this cut-off was able to discriminate and stratify patients' risk.
Patients with an intense drop of Alb on POD $1(\Delta \mathrm{Alb}$ POD $1 \geq 10 \mathrm{~g} / \mathrm{L}$ ) showed a higher mE-PASS (0.73 vs 0.49 , $\mathrm{p}=0.029)$ with higher rates of minor $(36 \%$ vs $15 \%$, $\mathrm{p}=0.011)$, major $(28 \%$ vs $6 \%, \mathrm{p}=0.002)$ and overall complications $(64 \%$ vs $20 \%, \mathrm{p}<0.001)$. This resulted in a significantly higher CCI $(20.9$ vs $0, \mathrm{p}<0.001)$ and in a significantly longer LoS (13 vs 4 days, $\mathrm{p}<0.001$ ) (see online supplementary table S2).

Logistic regression with multivariable analysis identified open surgery (OR: 11.22; 95\% CI 2.74 to 46.05; $\mathrm{p}=0.001$ ) and $\triangle$ Alb POD $1 \geq 10 \mathrm{~g} / \mathrm{L}$ (OR: $3.29 ; 95 \%$ CI 1.14 to $9.49 ; \mathrm{p}=0.028)$ to be independently associated with overall complications (table 2).

\section{DISCUSSION}

Surgery induced a rapid decrease of serum albumin in patients undergoing elective major abdominal procedures; and it remained stable for several postoperative days. Although correlation coefficients were modest, the decrease in serum albumin significantly correlated with 

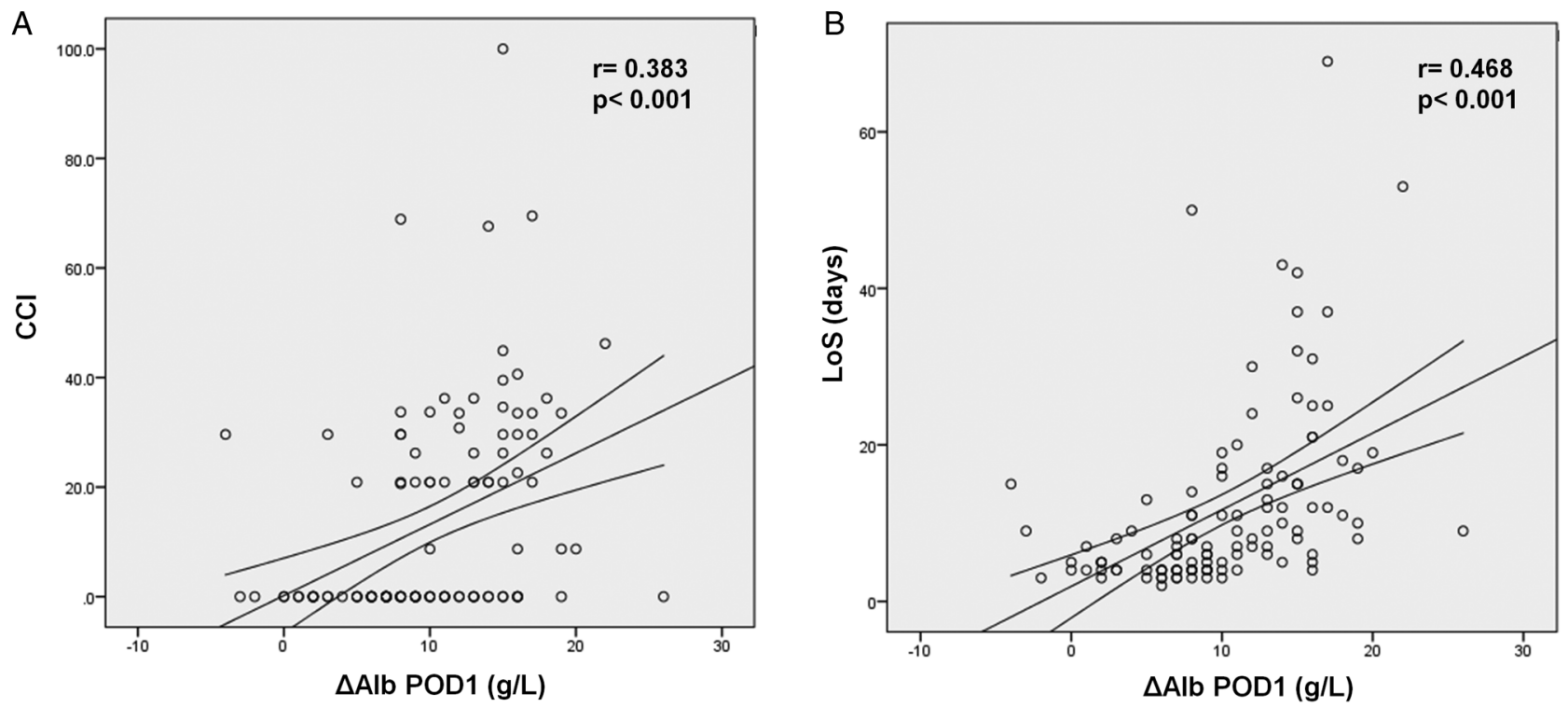

Figure 2 The postoperative decrease of Alb on POD 1 correlated with outcomes. $\triangle A$ Ib on POD1 showed a significant correlation with $\mathrm{CCl}$ (Comprehensive Complication Index) (A), and with length of stay (LoS) (B).

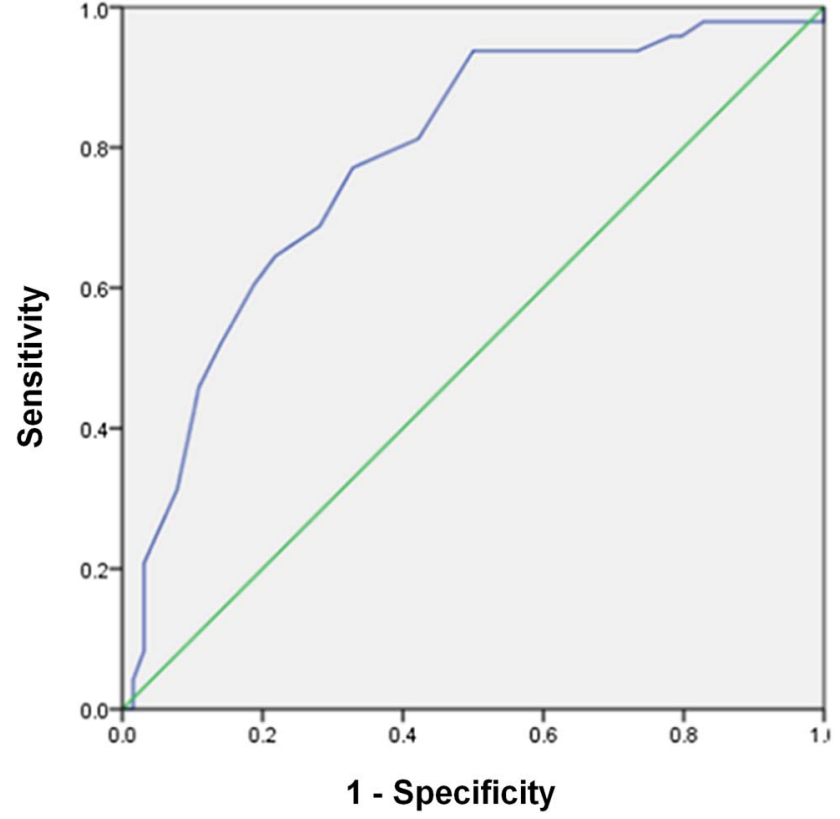

Figure 3 Receiver operating characteristic (ROC) curve to determine the optimal cut-off of $\triangle$ Alb on POD1 (blue line), showed an AUC of 0.78 .

(1) the extent of surgery (mE-PASS, blood loss, duration of surgery and surgical approach), (2) the maximal amplitude of other stress markers, such as CRP, PCT and LCT and (3) was consistently associated with adverse outcomes (according to Clavien classification, CCI, and $\mathrm{LoS})$. A serum albumin decrease $\geq 10 \mathrm{~g} / \mathrm{L}$ on POD 1 was independently associated with a threefold increased risk for postoperative complication.

The present study tested a panel of four biomarkers of which two are routinely used and served as benchmarks
(CRP and PCT) and two are less established markers and deserved prospective investigations (Alb and LCT). The mE-PASS accurately recapitulates surgical stress, and was validated and used in abdominal surgery. ${ }^{18} 21-24$ To the best of our knowledge, there is no other validated and available score. One study end point was the CCI, which is a score summing each complication graded according to the Clavien classification. As a result, CCI avoids omitting minor complications and is therefore more accurate than the Clavien classification alone. ${ }^{20}$ Serum albumin showed the more consistent correlation with stress response and clinical outcomes. Alb and LCT display some of the features for ideal markers: easy to measure and to interpret, readily available, can be repeated for monitoring and non-expensive. While Alb rapidly dropped after surgery and subsequently stabilised until POD 3, LCT showed a prompt increase followed by a fast return to baseline value, already on POD 1. It can be assumed that the timing of blood collection may have a more important impact on LCT than on Alb. As a consequence, Alb is more robust and easier to use in the clinical setting. Importantly, the selected markers were repeatedly measured, which allowed us to capture their perioperative profiles and to further calculate differences of concentrations between various time-points. The latter was revealed to be pivotal and more informative than a single value.

The mechanisms of early postoperative albumin decrease combine altered metabolism, blood loss/dilution and most importantly redistribution into the third space, due to capillary leakage. The latter accounts for $>75 \%$ of albumin decrease in the early postoperative phase and appears to be related to the magnitude of systemic inflammatory response. ${ }^{102526}$ Therefore, albumin decrease is certainly influenced by perioperative fluid 
Table 2 Logistic regression with univariable and multivariable analysis for predictors of postoperative complications

\begin{tabular}{|c|c|c|c|c|c|c|}
\hline & \multicolumn{6}{|c|}{ Overall postoperative complications } \\
\hline & \multicolumn{3}{|c|}{ Univariable } & \multicolumn{3}{|c|}{ Multivariable } \\
\hline & OR & $95 \% \mathrm{Cl}$ & p Value & OR & $95 \% \mathrm{Cl}$ & p Value \\
\hline Age $\geq 70$ years & 1.55 & 0.74 to 3.27 & 0.247 & & & \\
\hline Gender (female) & 0.45 & 0.22 to 0.89 & 0.022 & 1.06 & 0.38 to 2.96 & 0.905 \\
\hline ASA I/II & 1.33 & 0.66 to 2.68 & 0.42 & & & \\
\hline ECOG 0/1 & 1.83 & 0.79 to 4.28 & 0.161 & & & \\
\hline Cirrhosis & 2.66 & 0.24 to 30 & 0.43 & & & \\
\hline Cancer & 1.33 & 0.63 to 2.84 & 0.456 & & & \\
\hline Diabetes & 0.77 & 0.3 to 2 & 0.59 & & & \\
\hline $\mathrm{BMI} \geq 25 \mathrm{~kg} / \mathrm{m}^{2}$ & 0.59 & 0.3 to 1.17 & 0.129 & & & \\
\hline Approach (open) & 8.49 & 3.72 to 19.18 & $<0.001$ & 11.22 & 2.74 to 46.05 & 0.001 \\
\hline Duration $\geq 180 \mathrm{~min}$ & 4.48 & 2.12 to 9.47 & $<0.001$ & 0.47 & 0.11 to 1.94 & 0.297 \\
\hline Blood loss $\geq 200 \mathrm{~mL}$ & 4.50 & 2.19 to 9.25 & $<0.001$ & 1.68 & 0.57 to 4.99 & 0.350 \\
\hline$\Delta$ Alb POD $1 \geq 10 \mathrm{~g} / \mathrm{L}$ & 6.89 & 2.94 to 16.14 & $<0.001$ & 3.29 & 1.14 to 9.49 & 0.028 \\
\hline
\end{tabular}

management (liberal vs restrictive), but it mainly reflects the extent of postsurgical stress response.

In multivariable analysis (table 2), two factors were independently associated with complications: approach and $\triangle$ Alb POD $1 \geq 10 \mathrm{~g} / \mathrm{L}$. The overlap of certain parameters of surgical stress may, in part, explain why they were not identified as independent predictors of complications. It may also suggest that serum albumin mirrors these different parameters.

Some limitations need to be addressed. The present analyses were focused on four biomarkers that are readily available and easy to evaluate in the clinical setting. This non-inclusive panel of biomarkers could be perceived as a methodological shortcoming. Notwithstanding, integrating more complex and costly biomarkers would unlikely be more informative given their poor reproducibility, cost and assay measurement complexity. Likewise, this study did not assess the predictive value of albumin drop combined with other biomarker and/or clinical variables. Although such a classifier may presumably improve sensitivity and specificity, it will also be more complex which could ultimately preclude its implementation in clinical practice. Blood collection on POD 0 occurred 4-6 hours after the end of surgery. This delay might be long enough to alter the discriminatory ability of certain biomarkers, particularly lactate. ${ }^{27}$ Finally, the present findings need to be further validated with an independent cohort.

Available data on the predictive role of postoperative $\mathrm{Alb}$ are scarce; and most of these reports were retrospective studies. ${ }^{11-13} 1516$ Of note, each of the studies investigated only a single postoperative value of serum albumin. This represents a critical drawback as it cannot be discerned whether the low postoperative concentration of serum albumin resulted from intense surgical stress or from low preoperative level, which is an acknowledged predictor of increased postoperative complication. ${ }^{28} 29$ A prospective pilot study in abdominal surgery-conducted recently in our institution-showed consistent findings, with an increased risk of complication related to the amplitude of serum albumin postoperative drop. ${ }^{4}$ Of note, the cohorts from this previous study (70 patients) and from the present one (138 patients) were strictly distinct. Postoperative LCT has been more thoroughly explored in liver surgery, with few reports in other surgical fields. In a recent landmark study, Vibert $e t a l^{27}$ demonstrated that a postoperative cut-off of arterial LCT $>3 \mathrm{mmol} / \mathrm{L}$ at the end of surgery was an independent predictor of complications after elective hepatectomies. Their conclusion correlates with the present findings since $\triangle \mathrm{LCT}$ POD0 was correlated with mE-PASS $(p=0.039)$, overall complication $(\mathrm{p}<0.001)$, CCI $(\mathrm{p}=0.007)$ and LoS $(p=0.008)$ (figure 2). Although CRP and PCT are routinely used biomarkers in clinical practice, they are typically contributive on POD 4 only. The present study design allowed to confirm the ultimate advantage of Alb to be upregulated within the early postoperative phase, illustrated by the correlation between $\Delta$ Alb on POD1 and $\triangle \mathrm{CRP}$ on POD4 $(\mathrm{p}=0.234, \mathrm{p}=0.044)$, highlighted in this study. In fact, $\triangle \mathrm{Alb}$ on POD1 was more sensitive than $\triangle \mathrm{CRP}$ on POD4, illustrated by AUC of 0.78 and 0.75 , respectively (figure 3 and see online supplementary 3D).

How the monitoring of Alb in surgical patients can lead to better outcomes is a key question. Measures to preoperatively attenuate the stress response to surgery have been extensively explored. Interestingly, successful attempts were reported with immunonutrition, ${ }^{30}$ enhanced recovery programmes (ERAS), ${ }^{31} 32$ or high-dose glucocorticoids. ${ }^{33}$ Whether these options would be able to restrain the stress response, once triggered, in the early postoperative phase remains to be investigated. In this setting, albumin drop may indicate whether these measures may be beneficial in the perioperative period by being incorporated into the 
design of clinical trials as a marker for patients at higher risk of perioperative complications.

In summary, early postoperative decrease of serum albumin correlated with the (1) extent of surgery, (2) its metabolic response and with (3) adverse outcomes such as complications and LoS. A decreased concentration of serum albumin $\geq 10 \mathrm{~g} / \mathrm{L}$ on POD 1 was associated with a threefold increased risk of overall postoperative complications; albumin decrease occurs rapidly after surgery and remains stable for several days. As it is easy to measure, it could be used to identify patients at risk.

\section{Author affiliations}

Department of Visceral Surgery, Lausanne University Hospital CHUV, Lausanne, Switzerland

Contributors IL involved in study design, data collection, analysis and interpretation, review of the literature, drafting and critical revision of the manuscript. G-RJ involved in study design, data collection, analysis and interpretation, review of the literature and critical revision of the manuscript. AK involved in data collection, analysis and interpretation, review of the literature and critical revision of the manuscript. SM involved in data collection, analysis and interpretation, review of the literature and critical revision of the manuscript. MS and ND involved in study design, analysis and interpretation and critical revision of the manuscript. MH involved in study design, analysis and interpretation, drafting and critical revision of the manuscript.

Ethics statement The study was approved by the Institutional Review Board (No. 367/15)

Funding This research received no specific grant from any funding agency in the public, commercial or not-for-profit sectors.

Competing interests None declared.

Patient consent Obtained.

Provenance and peer review Not commissioned; externally peer reviewed.

Data sharing statement No additional data are available.

Open Access This is an Open Access article distributed in accordance with the Creative Commons Attribution Non Commercial (CC BY-NC 4.0) license, which permits others to distribute, remix, adapt, build upon this work noncommercially, and license their derivative works on different terms, provided the original work is properly cited and the use is non-commercial. See: http:// creativecommons.org/licenses/by-nc/4.0/

\section{REFERENCES}

1. Noordzij PG, Poldermans D, Schouten O, et al. Postoperative mortality in the Netherlands: a population-based analysis of surgery-specific risk in adults. Anesthesiology 2010;112:1105-15.

2. Vonlanthen R, Slankamenac K, Breitenstein S, et al. The impact of complications on costs of major surgical procedures: a cost analysis of 1200 patients. Ann Surg 2011;254:907-13.

3. Thorell A, Nygren J, Ljungqvist O. Insulin resistance: a marker of surgical stress. Curr Opin Clin Nutr Metab Care 1999;2:69-78.

4. Mantziari S, Hübner M, Coti-Bertrand $\mathrm{P}$, et al. A novel approach to major surgery: tracking its pathophysiologic footprints. World J Surg 2015;39:2641-51.

5. Kohl BA, Deutschman CS. The inflammatory response to surgery and trauma. Curr Opin Crit Care 2006;12:325-32.

6. Amar D, Zhang H, Park B, et al. Inflammation and outcome after general thoracic surgery. Eur J Cardiothorac Surg 2007;32:431-4.

7. Hall R. Identification of inflammatory mediators and their modulation by strategies for the management of the systemic inflammatory response during cardiac surgery. J Cardiothorac Vasc Anesth 2013;27:983-1033.

8. Facy $\mathrm{O}$, Paquette $\mathrm{B}$, Orry $\mathrm{D}$, et al. Diagnostic accuracy of inflammatory markers as early predictors of infection after elective colorectal surgery: results from the IMACORS study. Ann Surg 2016;263:961-6.
9. Giaccaglia V, Salvi PF, Antonelli MS, et al. Procalcitonin reveals early dehiscence in colorectal surgery: the PREDICS study. Ann Surg 2016;263:967-72.

10. Hübner M, Mantziari S, Demartines N, et al. Postoperative albumin drop is a marker for surgical stress and a predictor for clinical outcome: a pilot study. Gastroenterol Res Pract 2016;2016:8743187.

11. Ryan AM, Hearty A, Prichard RS, et al. Association of hypoalbuminemia on the first postoperative day and complications following esophagectomy. J Gastrointest Surg 2007;11:1355-60.

12. Lee JI, Kwon M, Roh JL, et al. Postoperative hypoalbuminemia as a risk factor for surgical site infection after oral cancer surgery. Oral Dis 2015;21:178-84.

13. Fujiwara $\mathrm{Y}$, Shiba $\mathrm{H}$, Shirai $\mathrm{Y}$, et al. Perioperative serum albumin correlates with postoperative pancreatic fistula after pancreaticoduodenectomy. Anticancer Res 2015;35:499-503.

14. Labgaa I, Joliat GR, Demartines N, et al. Serum albumin is an early predictor of complications after liver surgery. Dig Liver Dis 2016;48:559-61.

15. Sang BH, Bang JY, Song JG, et al. Hypoalbuminemia within two postoperative days is an independent risk factor for acute kidney injury following living donor liver transplantation: a propensity score analysis of 998 consecutive patients. Crit Care Med 2015;43:2552-61.

16. Lee $\mathrm{EH}$, Chin JH, Choi DK, et al. Postoperative hypoalbuminemia is associated with outcome in patients undergoing off-pump coronary artery bypass graft surgery. J Cardiothorac Vasc Anesth 2011;25:462-8.

17. Hübner M, Cerantola $Y$, Grass $F$, et al. Preoperative immunonutrition in patients at nutritional risk: results of a double-blinded randomized clinical trial. Eur J Clin Nutr 2012;66:850-5.

18. Haga $\mathrm{Y}$, Ikejiri $\mathrm{K}$, Wada $\mathrm{Y}$, et al. A multicenter prospective study of surgical audit systems. Ann Surg 2011;253:194-201.

19. Dindo D, Demartines N, Clavien PA. Classification of surgical complications: a new proposal with evaluation in a cohort of 6336 patients and results of a survey. Ann Surg 2004;240:205-13.

20. Slankamenac K, Graf R, Barkun J, et al. The comprehensive complication index: a novel continuous scale to measure surgical morbidity. Ann Surg 2013;258:1-7.

21. Haga $\mathrm{Y}$, Ikejiri $\mathrm{K}$, Takeuchi $\mathrm{H}$, et al. Value of general surgical risk models for predicting postoperative liver failure and mortality following liver surgery. J Surg Oncol 2012;106:898-904.

22. Haga $\mathrm{Y}$, Wada $\mathrm{Y}$, Takeuchi $\mathrm{H}$, et al. Evaluation of modified estimation of physiologic ability and surgical stress in gastric carcinoma surgery. Gastric Cancer 2012;15:7-14.

23. Haga $\mathrm{Y}$, Wada $\mathrm{Y}$, Takeuchi $\mathrm{H}$, et al. Evaluation of modified estimation of physiologic ability and surgical stress in patients undergoing surgery for choledochocystolithiasis. World J Surg 2014;38:1177-83.

24. Haga $Y$, Wada $Y$, Saitoh $T$, et al. Value of general surgical risk models for predicting postoperative morbidity and mortality in pancreatic resections for pancreatobiliary carcinomas. $J$ Hepatobiliary Pancreat Sci 2014;21:599-606.

25. Smeets HJ, Kievit J, Dulfer FT, et al. Analysis of post-operative hypalbuminaemia: a clinical study. Int Surg 1994;79:152-7.

26. Fleck A, Raines $G$, Hawker F, et al. Increased vascular permeability: a major cause of hypoalbuminaemia in disease and injury. Lancet 1985;1:781-4.

27. Vibert E, Boleslawski E, Cosse C, et al. Arterial lactate concentration at the end of an elective hepatectomy is an early predictor of the postoperative course and a potential surrogate of intraoperative events. Ann Surg 2015;262:787-93.

28. Poon RT, Fan ST, Lo CM, et al. Improving perioperative outcome expands the role of hepatectomy in management of benign and malignant hepatobiliary diseases: analysis of 1222 consecutive patients from a prospective database. Ann Surg 2004;240:698-708. discussion 08-10.

29. Uzunoglu FG, Reeh M, Vettorazzi E, et al. Preoperative Pancreatic Resection (PREPARE) score: a prospective multicenter-based morbidity risk score. Ann Surg 2014;260:857-63. discussion 63-4.

30. Cerantola $Y$, Hübner M, Grass $\mathrm{F}$, et al. Immunonutrition in gastrointestinal surgery. Br J Surg 2011;98:37-48.

31. Carli F. Physiologic considerations of enhanced recovery after surgery (ERAS) programs: implications of the stress response. Can $J$ Anaesth 2015;62:110-19.

32. Ljungqvist $\mathrm{O}$, Nygren J, Soop $\mathrm{M}$, et al. Metabolic perioperative management: novel concepts. Curr Opin Crit Care 2005;11:295-9.

33. de la Motte L, Kehlet H, Vogt K, et al. Preoperative methylprednisolone enhances recovery after endovascular aortic repair: a randomized, double-blind, placebo-controlled clinical trial. Ann Surg 2014;260:540-8. discussion 48-9. 